${ }^{\star}$ Graphical Abstract

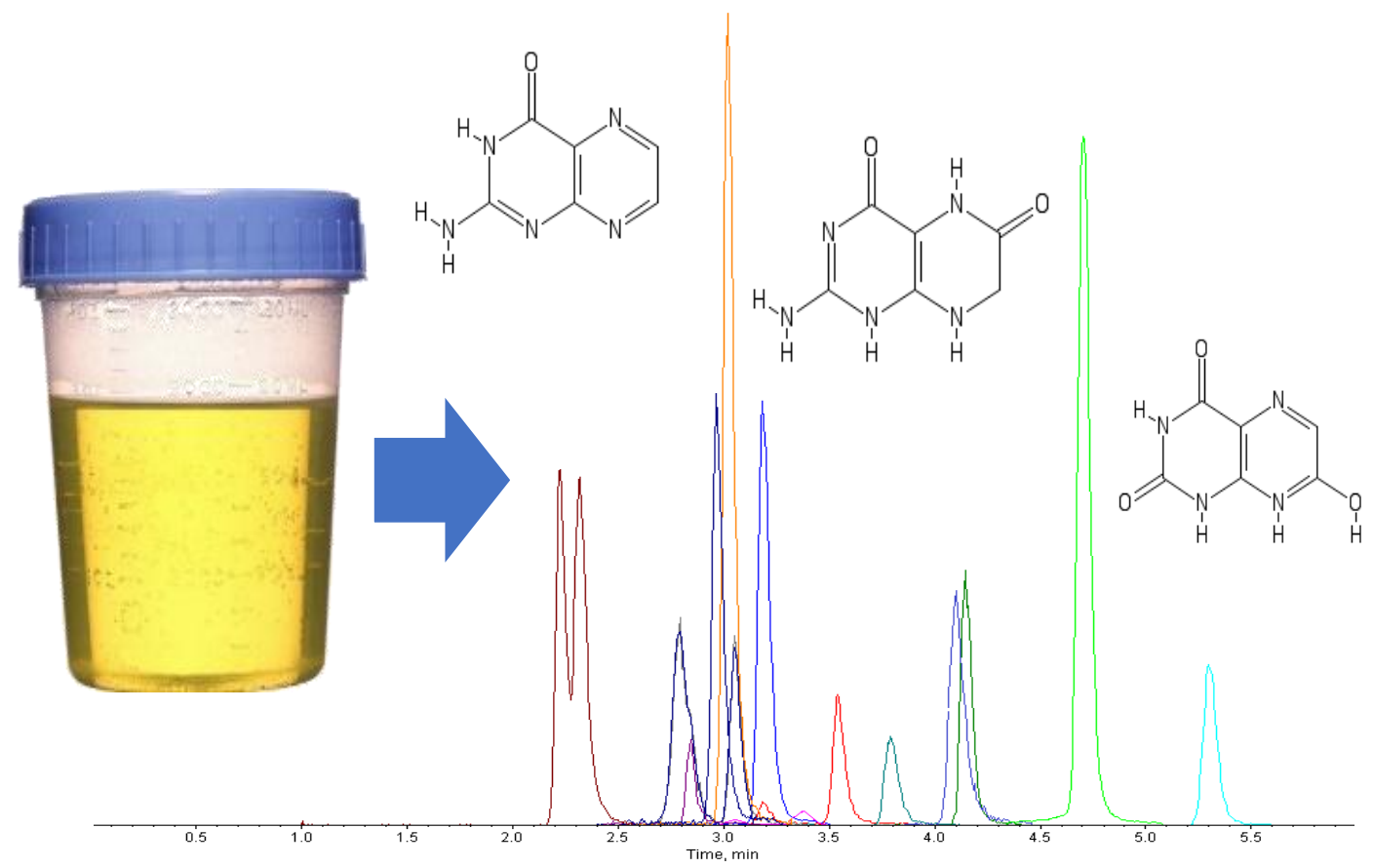




\title{
Development of a High-Performance Liquid Chromatography - Tandem Mass Spectrometry Urinary Pterinomics Workflow
}

\author{
Casey Burton, Honglan Shi, Yinfa Ma* \\ Department of Chemistry and Center for Single Cell, Single Nanoparticle, and Single Molecule \\ Monitoring, Missouri University of Science and Technology, Rolla, MO 65409 \\ * Corresponding Author \\ Address: Department of Chemistry \\ Missouri University of Science and Technology \\ 400 West 11th Street \\ Rolla, MO 65409 \\ Phone: 573-341-6220 \\ Fax: 573-341-6033 \\ E-mail: yinfa@mst.edu
}




\begin{abstract}
Pteridines have evoked considerable interest from the scientific community owing to their prominent roles in human health and disease. The availability of analytical methodologies suitable for comprehensive pteridine profiling, termed here as "pterinomics", has been limited by inconsistent sample preparation and the exclusion of lesser studied pteridine derivatives. In response, the present study describes a new pterinomics workflow using a high-performance liquid chromatography - tandem mass spectrometry (HPLC-MS/MS) methodology for the simultaneous analysis of 15 pteridine derivatives including five structural isomers, marking the largest quantitative pteridine panel that has been studied to-date. The validated method possessed excellent sensitivity with method detection limits $\left(0.025 \mu \mathrm{g} \mathrm{L}^{-1}\right.$ to $\left.0.5 \mu \mathrm{g} \mathrm{L}^{-1}\right)$ that were comparable or superior to existing techniques. Spiked recovery studies demonstrated the technique was both accurate (88-112\%) and precise (RSD: 0-6\%). A comparative study of commonly used oxidative pretreatments, including triiodide, permanganate, and manganese dioxide, revealed that the oxidative mechanisms were inefficient, complex, and concentration dependent. Finally, 50 clinical urine specimens were examined with the new technique wherein 10 pteridine derivatives were quantified and population ranges have been given. This technique can be used to examine pteridine molecular epidemiology and biochemistry to support related research applications, and may further be readily extended to include additional pteridine derivatives and biological matrices for specific applications.
\end{abstract}

\title{
Key words: Pteridines, oxidative pretreatment, urine, HPLC-MS/MS, pterinomics
}




\section{Introduction}

Pteridines have evoked interest from the scientific community since their successful isolation from butterfly wings by Hopkins in 1889 [1]. The structural elucidation of their pyrazine $[2,3-D]$ pyrimidine ring system that followed in the early 1940 s prompted tremendous efforts to catalogue their biological and chemical diversity that continue to this day [2-4]. From these studies have emerged an extensive and complex family of metabolites related to the biosynthesis and biodegradation of vitamins and cofactors [5]. The key finding that 5,6,7,8-tetrahydrobiopterin is an obligatory cofactor for aromatic amino acid hydroxylases $[6,7]$ and nitric oxide synthase $[8,9]$, as well as the cytokine-inducible biosynthesis of neopterin $[10$, 11], has furthered research into the function of pteridine derivatives in human health and disease. In recent years, these efforts have expanded to include the aromatic pteridines derived from folic acid catabolism [12], including 6-formylpterin, 6-carboxypterin, 6-hydroxymethylpterin, pterin, and isoxanthopterin [13]. Aromatic pteridines, and to lesser extents their semi-reduced and reduced counterparts, have remarkable photocatalytic and oxidoreductive properties, including a considerable capacity to generate reactive oxygen species [14-17] and even photosensitize important biomolecules including DNA [18-20], folic acid [21], and tryptophan [22], which has led researchers to postulate that pteridines may actively participate in molecular pathology [13]. Similarly, the overexpression of the endocytic folate receptor $\alpha$ in solid epithelial tumors [23-25] has presented a novel pathomechanistic premise for the clinical observation of elevated levels of folate-derived pteridines in the urine of patients suffering from lung and colon cancers [26], bladder cancer [27, 28], breast cancer [26, 29, 30], digestive tract cancers [31], and brain tumors 
[32].

However, current understanding on the biochemistry and molecular pathology of mammalian pteridines remains fragmented [33]. As Rembold and Gyure presciently remarked over forty years ago, analytical limitations related to the general instability and trace levels of biogenic pteridines have precluded detailed studies of the prevalence and role of many lesser known derivatives $[13,34]$. More recent efforts have seen an attempt to develop robust analytical methodologies using advanced instrumental platforms and oxidative pretreatments to enable sensitive detection of biologically significant pteridine derivatives. To this end, a multitude of competent analytical techniques have emerged over the past several years using an array of sensitive instrumental platforms including capillary electrophoresis - laser-induced fluorescence (CE-LIF) [35], high-performance liquid chromatography - fluorescence detection (HPLC-FD) [28, 36-40], high-performance liquid chromatography - mass spectrometry (HPLC-MS) [41], high-performance liquid chromatography - tandem mass spectrometry (HPLC-MS/MS) [29, 42-44], hydrophilic interaction chromatography - tandem mass spectrometry (HILIC-MS/MS) [45], and synchronous fluorescence spectroscopy [46, 47], which have been summarized in

Table 1.

Nevertheless, the availability of analytical methods suitable for comprehensive pteridine analysis, termed here as "pterinomics", has been limited by several notable factors. First, fragmented understanding of the pteridine biosynthetic pathway alongside the tendency to select pteridine derivatives with previously established biological significance have generally limited the inclusion of lesser known derivatives in new analytical techniques. The interconversion of 
6-substituted pteridines to 7-substituted isomers via biochemical processes that are unrelated to classical pteridine biosynthetic pathways presents an additional class of pteridine derivatives with probable biological significance that have otherwise received little attention thus far [48, 49]. Secondly, the problematic practice of using a variety of oxidative and anti-oxidative pretreatments, as recently reviewed by Tomšíková and co-workers [50], has led to inconclusive or inconsistent findings. Although a number of oxidative pretreatments have been proposed and optimized for selected pteridine derivatives, comparative studies of oxidative efficiency and byproduct formation for a wide panel of pteridine derivatives are lacking. An alternative strategy to oxidative pretreatments has more recently focused on the investigation of pteridine derivatives in their native oxidative states $[40-42,51]$, although the relative abundance and interconversion of semi-reduced and reduced pteridine derivatives in biological fluids, and particularly urine, remains disputed [36, 52-54]. For these reasons, new methods are urgently needed to study expanded pteridine panels, including structural isomers, alongside improved knowledge on the effectiveness of oxidative pretreatments to advance pteridine research in human health and disease.

In the present study, we described a new workflow for the quantitative analysis of 15 pteridine derivatives in urine using a novel HPLC-MS/MS methodology. The pteridines investigated in this study were selected primarily as folate-derived pteridines with cancer biomarker applications [55] and include five structural isomers, multiple lesser known derivatives, and two semi-reduced compounds (Figure 1). However, the analytical workflow has been designed with extensibility to additional pteridine derivatives and biological matrices for 
specific applications. This new technique was subsequently used to systematically study the in-source oxidation, interconversion, and efficiency of several commonly used oxidative pretreatments in an attempt to standardize pteridine sample preparation. The resulting standardized technique was used to profile pteridine derivatives in the urine of healthy individuals, breast cancer patients, and prostate cancer patients.

\section{Materials and Methods}

\subsection{Chemicals and Materials}

Pterin, xanthopterin, 7,8-dihydroxanthopterin, isoxanthopterin, 6-biopterin, sepiapterin, neopterin, monapterin, 6-carboxypterin, 6-hydroxymethylpterin, 6,7-dimethylpterin, 6-methylpterin, lumazine, 6-hydroxylumazine, 7-hydroxylumazine, 6-formylpterin, leucopterin, and folic acid were purchased from Schircks Laboratory (Jona, Switzerland). LC-MS grade ammonium hydroxide and formic acid were purchased from Fisher Scientific (New Jersey, USA). Potassium iodide, iodine, ascorbic acid, and dithiothreitol were purchased from Sigma-Aldrich (St. Louis, USA). Synthetic urine was obtained from CST Technologies Inc. (New York, USA). Ultrapure water was generated by a Milli-Q Advantage ${ }^{\circledR}$ A10 and Millipore Elix ${ }^{\circledR}$ water purification system.

\section{$\underline{2.2 \text { Instrumentation }}$}

Pteridine derivatives were separated using a Luna phenyl-hexyl column $(3.0 \mu \mathrm{m}, 3.0 \times 150$ $\mathrm{mm}$ ) and accompanying guard column (Phenomenex, Torrance, CA) in conjunction with a 
Shimadzu UFLC system (Columbia, MD) that included a degasser (DGU-30A3), two pumps (LC-20 AD XR), a temperature controlled autosampler (SIL-20AC XR) and a column oven (CTO-20A). Chromatography was performed at $40^{\circ} \mathrm{C}$ with a flow rate of $0.45 \mathrm{~mL} \mathrm{~min}^{-1}$ using a $50 \mu \mathrm{L}$ injection volume. A binary gradient flow system was used to separate pteridine derivatives using the following mobile phase compositions: A: $0.025 \%(\mathrm{v} / \mathrm{v})$ formic acid in $99 \%$ water / $1 \%$ acetonitrile; B: methanol. The gradient profile included an initial two-minute period in which the composition of mobile phase B was increased linearly from $7 \%$ to $20 \%$, followed by another two-minute period in which mobile phase B was held at $20 \%$, and rapidly returned to $7 \%$ for the final two minutes. A one-minute pre-equilibration as well as a $200 \mu \mathrm{L}$ post-injection needle rinse procedure were added to reduce carryover effects between biological samples. The total run-to-run time was 7.0 minutes. Samples were stored in the autosampler at $4^{\circ} \mathrm{C}$ for a period lasting no longer than six hours

An AB Sciex 4000 QTrap MS/MS system (Foster City, CA, USA) was used to quantify pteridine derivatives. The ion source was operated in positive-ion ESI mode with the following flow injection parameters: ion spray voltage: $+5500 \mathrm{~V}$; source temperature: $600^{\circ} \mathrm{C}$; curtain gas: 45 psi $\mathrm{N}_{2}$; GS1: 25 psi $\mathrm{N}_{2}$; GS2: 35 psi $\mathrm{N}_{2}$; heated interface. Scheduled multiple reaction monitoring (MRM) experiments were operated with 44 second scan windows and individual target scan times of 0.7 seconds to quantify selected ions transitions. Collisionally-activated dissociation (CAD) of pteridine derivatives was achieved using 12 psi ultra-pure $\mathrm{N}_{2}$ gas in the collision chamber. 


\section{$\underline{2.3 \text { Standard Preparation }}$}

Between 2 and $5 \mathrm{mg}$ of each pteridine standard was dissolved in in $13 \mathrm{~mL}$ of ultrapure water and $500 \mu \mathrm{L}$ of $2 \mathrm{~N}$ ammonium hydroxide in amber glass vials. Sonication was used to enhance dissolution of poorly soluble species, namely, 6,7-dimethylpterin, 6-methylpterin, pterin, and leucopterin. Dilutions from these individual standard stock solutions were used for direct infusion analysis to optimize MS/MS conditions. A stock mixture solution was similarly prepared at $10 \mathrm{mg} / \mathrm{L}$ each component from these individual stock solutions using ultra-pure water. Aliquots of the individual and stock mixture solutions were wrapped in aluminum foil and were stored at $-80^{\circ} \mathrm{C}$. Fresh calibration standards were prepared from these aliquots daily using serial dilutions in ultra-pure water and/or $1 \%$ synthetic urine.

\section{$\underline{2.4 \text { Analysis of Urine Samples }}$}

Urine specimens $(n=50)$ were collected from consenting women 33-87 years of age (mean: 60.0 years) at Mercy Breast Center - Springfield (Springfield, MO) between October 2014 and December 2014 in a consecutive case series manner. Selection criteria included women referred to the medical center for biopsy characterization with no co-present medical conditions or previous history of cancer. Participants were drawn from a local patient population with the following demographics: $88.7 \%$ Caucasian, 3.3\% Hispanic or Latino, 3.2\% African American, $1.8 \%$ Asian, and $3 \%$ other or two or more races. Spot urine specimens consisting of first morning and second morning voids were collected prior to biopsy and immediately stored at $-20^{\circ} \mathrm{C}$ for $1-6$ days. Specimens were shipped to Missouri University of Science and Technology for analysis via 
next-day frozen ground freight. Upon arrival, specimens were thawed, aliquoted, and refrozen at $-80^{\circ} \mathrm{C}$ until analysis. Mercy Breast Center pathologists disclosed anonymized diagnostic reports at the conclusion of the study.

Under dark conditions, urine sample aliquots were gradually thawed to room temperature and thoroughly vortexed. The urine specific gravity (USG) was determined from $200 \mu \mathrm{L}$ sample using a temperature-corrected Reichert TS 400 clinical refractometer. USG was used to adjust urinary pteridine concentrations to patient hydration-dilution status and time since last urination in accordance with prior work [30]. Another $100 \mu \mathrm{L}$ sample was diluted tenfold in ultra-pure water in a yellow centrifuge tube. Diluted samples were centrifuged at $3000 \mathrm{~g}$ for 20 minutes at $4^{\circ} \mathrm{C}$ and filtered with a $0.22 \mu \mathrm{m}$ Nylon membrane to remove sediment, proteins, and epithelial cells. Another tenfold dilution in ultra-pure water was made into a $1.5 \mathrm{~mL}$ amber glass vial and was subsequently vortexed and submitted to HPLC-MS/MS analysis. The total dilution factor for urine samples was 100-fold.

\section{Results and discussion}

\subsection{MS/MS Optimization}

Individual pteridine derivatives were infused at a concentration of $100 \mu \mathrm{g} \mathrm{L}^{-1}$ in mobile phase $\mathrm{A}\left(0.025 \%(\mathrm{v} / \mathrm{v})\right.$ formic acid in $99 \%$ water $/ 1 \%$ acetonitrile) at a flow rate of $0.2 \mathrm{~mL} \mathrm{hour}^{-1}$. Ion source conditions included: ion spray voltage: $+5500 \mathrm{~V}$; source temperature: $30^{\circ} \mathrm{C}$; curtain gas: 10 psi $\mathrm{N}_{2}$; GS1: 10 psi $\mathrm{N}_{2}$; GS2: 10 psi $\mathrm{N}_{2}$; heated interface. A combination of quadrupole (Q1) and linear ion trap (EMS) survey scans operating under Multiple Channel Analyzer (MCA) 
mode were used to study pseudomolecular ions. Sodiated and ammoniated molecular ions were present in standard stock solutions, owing to the dissolution of pteridine derivatives in ammonium hydroxide and ubiquitous sodium, respectively. The relative contributions of these adducts were consistent with previous reports [29], which may be generalized as the following: pteridines with electron withdrawing substituents favored the formation of ammoniated molecular ions whereas unsubstituted pteridines and pteridines with electron donating substituents favored the formation of sodiated molecular ions. Since molecular adducts contribute to decreased sensitivity and may require complicated ion summing procedures, infusion analysis of pteridine standards in $1 \%$ synthetic urine was performed to study adduct formation under simulated salt concentrations. In this case, ammoniated molecular ions were not significantly observed while sodiated molecular ions remained prevalent. Sodiation was effectively controlled by applying sufficiently high declustering potentials to the orifice, which was automatically optimized by the Analyst 1.5.2 software.

In addition to pteridine ammoniation and sodiation, 6-formylpterin exhibited in-source oxidation to 6-carboxypterin (approximately $60 \%$ of the $[\mathrm{M}+\mathrm{H}]^{+}$molecular ion) as well as significant $[\mathrm{M}+15]^{+}$and $[\mathrm{M}+\mathrm{H}+32]^{+}$molecular ions in the presence of methanol (representing $20 \%$ and $50 \%$ of the $[\mathrm{M}+\mathrm{H}]^{+}$molecular ion, respectively). The latter two ions were attributed to gas-phase aldol reactions between protonated aromatic aldehydes and methanol in the ion source [56]. These two species also did not appear in the linear ion trap EMS scans. Co-infusion of 100 $\mu \mathrm{M}$ ascorbic acid or dithiothreitol was found to limit its in-source oxidation to 6-carboxypterin. Furthermore, 6-formylpterin and 6,7-dimethylpterin are isobaric compounds with nearly 
identical fragmentation spectra with the exceptions of $\mathrm{m} / \mathrm{z} 106$ derived from 6,7-dimethylpterin and $m / z$ 67, 92, and 119 derived from 6-formylpterin. Commonly used ion transitions for these compounds, such as $192 \rightarrow 147$ and $192 \rightarrow 165$, should be avoided since these two pteridine derivatives have similar chromatographic retention times on conventional columns [29, 43]. In addition to its negligible solubility in aqueous solutions, leucopterin suffered poor ionization efficiencies where only high declustering potentials resulted in a weak $[\mathrm{M}+\mathrm{H}]^{+}$molecular ion and a weak $[\mathrm{M}-36]^{+}$molecular ion related to loss of water from its two ketone functionalities. For these reasons, leucopterin was not added to the current HPLC-MS/MS method. 7,8-Dihydroxanthopterin was found to have exhibited negligible in-source oxidation to xanthopterin $\left(<5 \%\right.$ of the $[\mathrm{M}+\mathrm{H}]^{+}$molecular ion). The limited extent of this in-source oxidation was contradictory to recent reports by Van Daele and co-workers who suggested a thermally facilitated oxidative process [43]. However, infusion at higher temperatures (e.g. $\left.500^{\circ} \mathrm{C}\right) \mathrm{did}$ not meaningfully increase in-source oxidation rates; rather, in-source oxidation of 7,8-dihydroxanthopterin appeared to be solvent mediated and may be manipulated by additive selection (e.g. acetic acid). A more detailed discussion on the oxidation of 7,8-dihydroxanthopterin and its derivatives is provided in the following sections.

The optimized MRM transitions have been summarized in Table 2. Flow injection analysis was performed for these optimized MRM transitions to enable systematic optimization of the ion source parameters. 


\section{$\underline{3.2 \text { HPLC Optimization }}$}

Separation parameters were initially adapted from a previously developed HPLC method using a Luna phenyl-hexyl column [29]. However, using $0.1 \%$ aqueous formic acid and acetonitrile resulted in co-elution of three of the four structural isomer pairs (Supplementary Figure 1). Adaptation of the selective HPLC technique developed by Girón and colleagues, in which the prescribed Zorbax Eclipse XDB-C18 column was substituted with a Kinetex C18 column $(2.6 \mu \mathrm{m}, 3.0 \times 150 \mathrm{~mm})$, similarly failed to separate isobaric compounds and at greatly increased run times. Since acetonitrile and formic acid contain pi electrons that can suppress pi-pi interactions between analytes and phenyl bonded phases, the Luna phenyl-hexyl column was reevaluated using methanol and lower formic acid compositions. Separation of the neopterin/monapterin and 6-hydroxylumazine/7-hydroxylumazine isomer pairs were inversely affected by solvent composition, where high formic acid concentrations $(>0.1 \% \mathrm{v} / \mathrm{v})$ promoted neopterin/monapterin separation and high acetonitrile compositions promoted 6-hydroxylumazine/7-hydroxylumazine separation. Overall method selectivity was greatly improved using methanol and sufficient amounts of formic acid for efficient analyte ionization. Therefore, trace amounts of acetonitrile were added to the aqueous phase to enable separation of the hydroxylumazines. The optimal solvent composition that permitted separation of isobaric pairs at minimal run times was determined to be $0.025 \% \mathrm{v} / \mathrm{v}$ formic acid in $99: 1 \%$ water:acetonitrile and pure methanol.

Furthermore, elevated column temperatures enhanced the separation of the hydroxylumazines, xanthopterin and isoxanthopterin, but partially merged neopterin and monapterin. It should be 
noted that 6-formylpterin and folic acid exhibited large peak widths and asymmetry on the reversed-phase Luna phenyl-hexyl column, which have been reported elsewhere [57]. The Kinetex C18 column meanwhile demonstrated superior selectivity and retention for these compounds. However, since the abundance of folic acid in urine relative to its primary degradation products, para-aminobenzoylglutamate (pABG) and para-acetamidobenzoylglutamate (apABG), is minimal [58], and 6-formylpterin is considered a reactive species that is not appreciably present in urine, both folic acid and 6-formylpterin were excluded from the validated method. Future studies aiming to quantify folic acid degradation byproducts such as 6-formylpterin should utilize alkyl- or polar-bonded phases. An optimized overlaid extraction ion chromatogram (XIC) of the quantitative ion pairs has been provided in

\section{Figure 2.}

Since urine is a complex matrix, potential interferences with equivalent MRM transitions and precursor ions were identified using unscheduled MRM experiments and linear ion trap enhanced product ion (EPI) scans. The EPI results were used in combination with MassBank spectral databases and chemical reference standards to make tentative assignments. Special attention was given to the presence of reduced pteridine derivatives, such as 5,6,7,8-tetrahydrobiopterin, that were not included in the pteridine panel investigated in this study. For example, 7,8-dihydrobiopterin was observed at approximately $2.85 \mathrm{~min}$ in untreated urine. In-source oxidation of 5,6,7,8-tetrahydrobiopterin chemical reference standard and EPI fragmentation patterns that matched those reported by Fismen et al [52] strongly suggested that this compound was 7,8-dihydrobiopterin. Similarly, a small peak at 2.1 min was observed using 
the MRM transition for neopterin/monapterin. Survey scans at this chromatographic time point suggested the presence of 7,8-dihydroneopterin, as evidenced by major fragmentation patterns that included $256 \rightarrow 165,178$ [43]. An unidentified compound that partially eluted with pterin was found to have the following ion transitions $164 \rightarrow 61,73,87,101,103,119,147$, including the shared $164 \rightarrow 119$ transition. For this reason, the less abundant $m / z 92$ fragment of pterin was selected as the quantitation ion. Tentative assignments were made for 7-methylguanine (R.T. $=$ $3.15 \mathrm{~min})$ and phenylalanine $($ R.T. $=4.10 \mathrm{~min})$ while searching for 7,8-dihydropterin $(\mathrm{m} / \mathrm{z}, 166)$. Tyrosine (R.T. $=3.1 \mathrm{~min}$ ) was also identified at $\mathrm{m} / \mathrm{z}, 182$ with dissimilar fragmentation to 7,8-dihydroxanthopterin. Interestingly, a significant peak was located at $\mathrm{m} / \mathrm{z}, 180$ at $4.2 \mathrm{~min}$ with a fragmentation pattern analogous to xanthopterin and isoxanthopterin. Further characterization revealed major fragmentation pathways of $180 \rightarrow 71,110$ and minor fragmentation pathways of $180 \rightarrow 68,80,93,108,135$, and 137 . This pattern appeared to be indicative of pyrazine ring opening in xanthopterin, although its occurrence could not be modulated by triiodide and UV oxidative pretreatments. Further characterization will be required for structural assignment.

\subsection{Comparative Study of Oxidative Pretreatments}

As Tomšíková and co-workers recently reviewed, a remarkably large number of oxidative and antioxidative pretreatments have been used to quantify pteridines in biological matrices [50]. Since comparative studies of these pretreatments have been incomplete or lacking, particularly in regard to semi-reduced and folate-derived pteridines like 7,8-dihydroxanthopterin, the newly developed HPLC-MS/MS method was used to quantify the oxidative efficiency of several 
commonly used techniques, including Lugol's solution $\left(\mathrm{I}_{3}^{-}\right)$, manganese dioxide, and potassium permanganate. Specifically, Lugol's solution, comprising a 4\%:2\% (w/v) mixture of potassium iodide-iodine, is the most commonly used oxidative pretreatment for pteridine analysis and was evaluated herein in both alkaline and acidic environments per previously developed protocol [27, 35, 37]. Permanganate and acidic manganese dioxide oxidative efficiency were also investigated using earlier developed methods $[28,44]$. A summarized comparison of the effects of these pretreatments on pteridine standards prepared in synthetic urine has been provided in Table 3 . From these data it becomes clear that oxidative pretreatment leads to degradation of both aromatic and reduced pteridine derivatives. Alkaline triiodide was considered the gentlest pretreatment strategy with the exceptions of pteridines with electron withdrawing substituents at the 6-position, such as xanthopterin, 6-carboxypterin, and 6-hydroxylumazine. However, the oxidation of 7,8-dihydroxanthopterin was remarkably complex with mass balance calculations indicating that the oxidative efficiency of the preferred conversion to xanthopterin was only $7 \%$. Infusion of untreated and oxidized 7,8-dihydroxanthopterin revealed possible oxidative byproducts centered at $m / z, 175,205$, and 213 , although the structures of these compounds remain undefined. An additional 5\% of 7,8-dihydroxanthopterin was lost to in-source oxidation during ionization. Acidic triiodide performed similarly to alkaline triiodide with the notable absence of xanthopterin which eluted much later $($ R.T. $=7.2 \mathrm{~min})$. The effect of triiodide concentration was also considered by comparing a typical addition of $150 \mu \mathrm{M}$ to $15 \mu \mathrm{M}$ where higher concentrations led to increased pteridine degradation. The possibility that this observation may be attributed to ion suppression rather than an oxidative reaction was rejected since iodide 
ions were found to elute at the column dead time under similar chromatographic conditions. Permanganate pretreatments resulted in substantial loss of both aromatic and semi-reduced pteridines. These permanganate findings generally agreed with those reported by Kośliński and colleagues, and were attributed to opening of the pteridine ring system [28]. Similarly, pretreatments using manganese dioxide contributed to relative losses for most pteridine derivatives.

In another experiment, we examined the effect of urine concentration-dilution on oxidative efficiency and pteridine degradation. Since synthetic urine lacks the pool of oxidizable species present in real urine matrices, it was necessary to investigate this effect using real urine samples. Alkaline triiodide was selected as the model oxidant owing to its widespread use and its relatively gentle oxidation. Urine concentration-dilution was indirectly modeled using USG, a correlate of total dissolved solids, as a surrogate [30]. The percentage of pteridine derivative remaining in oxidized urine specimens, relative to corresponding untreated urine specimens, were compared with sample USG ranging from 1.005 to 1.027 . Urine specimens $(n=10)$ were spiked with a $5 \mu \mathrm{g} \mathrm{L}^{-1}$ mixture of pteridine standards to ensure detection of all pteridine derivatives. Briefly, xanthopterin oxidation exhibited a strong positive correlation (Pearson's $r=$ 0.9949) with urine concentration-dilution, ranging from 50\% to 648\% initial levels. Similarly, 6-biopterin oxidation positively correlated with urine concentration-dilution (Pearson's $r=$ 0.9566 ) and ranged from $135 \%$ to $186 \%$ initial levels. These correlations were attributed to the oxidation of reduced derivatives of xanthopterin and 6-biopterin. However, neopterin oxidation was inversely related to urine concentration-dilution (Pearson's $r=-0.9957$ ), ranging from $72 \%$ 
in the 1.027 USG sample to $101 \%$ in the 1.005 USG sample. Other pteridine derivatives that exhibited correlations to urine concentration-dilution included 6-hydroxymethylpterin (Pearon's $r=0.9781$ ), monapterin (Pearson's $r=-0.9104$ ), and pterin (Pearson's $r=0.7211$ ). The oxidative effects on the other pteridines were generally similar to those determined in synthetic urine found in Table 3. These new findings are significant because previous research efforts have questioned whether triiodide ions have been provided in excess to ensure complete reduced pteridine oxidation $[27,35]$. This oxidative pretreatment dependence on urine concentration-dilution marks a novel discovery and questions the validity of using oxidative pretreatments for pteridine quantitation. Moreover, the discovery of complicated oxidation mechanisms in the case of 7,8-dihydroxanthopterin casts further doubts on the utility of oxidative pretreatments. While other analytical techniques have foregone pretreatment to simplify analysis or to preserve reduced species $[38,39,42,43]$, the present work has now provided compelling and quantitative evidence that currently used oxidative pretreatments are inefficient for quantitative pterinomics.

\subsection{Method Performance}

Performance characteristics for the newly described HPLC-MS/MS method have been summarized in Table 4. Analytical sensitivity, assessed in terms of method detection limits (MDLs) and lower limits of quantitation (LLOQs), was comparable or superior to existing techniques for pteridine quantitation with MDLs ranging from $0.025 \mu \mathrm{g} \mathrm{L}^{-1}$ to $0.5 \mu \mathrm{g} \mathrm{L}^{-1}$. Pteridine signal response exhibited considerable linearity $\left(\mathrm{R}^{2}>0.99\right)$ over a wide linear range that spanned several orders of magnitude. The abundance of 7,8-dihydroxanthopterin in urine 
specimens, which is discussed below, necessitated a higher operating range up to $1000 \mu \mathrm{g} \mathrm{L}^{-1}$.

Method accuracy was evaluated with spiked recoveries in a pooled urine specimen $(\mathrm{USG}=1.015)$ which ranged from $88 \%$ for low concentrations of 6-carboxypterin to $112 \%$ for high concentrations of 7,8-dihydroxanthopterin. The method possessed excellent precision that remained below $6 \%$ relative standard deviation for all pteridine derivatives on both intra-daily and inter-daily bases $(n=5)$. This level of precision was consistent across concentrations as indicated by the spiked recovery study.

\subsection{Analysis of Urine Specimens}

The new pterinomics workflow was applied to 50 clinical urine specimens from women who were diagnosed with either breast cancer or a benign fibrocystic conditions. This application was selected based on prior reports on the molecular epidemiology of pteridines in breast cancer [ 26 , 30], but also to determine whether untreated pteridine derivatives were present in urine at detectable concentrations. The latter investigation is novel because prior studies either have monitored reduced pteridine derivatives in other biological fluids or have used inferior methodologies that lack selectivity [39, 43]. At 100-fold dilution, ten of the fifteen pteridine derivatives were reliably quantified in all urine specimens (Figure 3). Those derivatives and their encountered concentration range were as follows: sepiapterin $(22 \mathrm{nM}-4500 \mathrm{nM})$, isoxanthopterin $(250 \mathrm{nM}-2010 \mathrm{nM})$, xanthopterin $(320 \mathrm{nM}-6000 \mathrm{nM})$, 6-biopterin $(0.1 \mu \mathrm{M}-$ $9.7 \mu \mathrm{M})$, neopterin $(0.2 \mu \mathrm{M}-26 \mu \mathrm{M})$, lumazine $(190 \mathrm{nM}-1000 \mathrm{nM})$, 7-hydroxylumazine (67 $\mathrm{nM}-465 \mathrm{nM})$, monapterin $(50 \mathrm{nM}-2400 \mathrm{nM})$, pterin $(150 \mathrm{nM}-2340 \mathrm{nM})$, and 
7,8-dihydroxanthopterin $(5 \mu \mathrm{M}-112 \mu \mathrm{M})$. 6-Carboxypterin was present in most urine

specimens, but at levels that were not quantifiable (signal-to-noise range: $0-4.2$ ), an observation that supports earlier research findings [29]. Similarly, 6-hydroxymethylpterin was observed in a majority of samples, but at unquantifiable levels (signal-to-noise range: $0-2.9$ ). Incomplete separation of neopterin and monapterin coupled with large concentration differences complicated the quantitation of monapterin. Detection of trace pteridines was improved by using lesser dilutions, such as 20-fold dilutions; however, a 100-fold dilution was preferable in order to increase longevity of the column and mass spectrometer [29]. Non-parametric Mann-Whitney $U$ group comparison tests revealed that no pteridine derivatives were substantially altered between the two patient groups, although isoxanthopterin $(p$-value $=0.063)$ was non-significantly increased in the breast cancer group. Hence, future studies that aim to quantify urinary levels of 6,7-dimethylpterin, 6-carboxypterin, 6-methylpterin, 6-hydroxymethylpterin, and 6-hydroxylumazine may require additional preconcentration or injection at lower dilutions.

Finally, much attention has been given to the stability and interconversion of reduced and aromatic pteridine derivatives in oxygenated and aqueous environments [50]. Prior work has shown that aromatic pteridines are generally stable at low temperatures, while the stability of semi-reduced pteridines is considerably less, but still significant [59]. This led us to investigate whether the pteridine profile of fresh urine specimens significantly differed from that of aged urine specimens. Interestingly, 7,8-dihydroxanthopterin was present in fresh urine and accumulated over a period of weeks and months. This phenomenon was attributed to the non-specific oxidation and hydration of reduced pteridine derivatives to 7,8-dihydroxanthopterin 


\section{Conclusion}

A new pterinomics workflow for the simultaneous determination of 15 pteridine derivatives in urine using HPLC-MS/MS has been described. The methodology expands on previous techniques by characterizing molecular adduction in ESI sources, separating five structural isomers, and investigating potential interferences present in complex urine matrices for the first time. The validated method possessed excellent sensitivity and precision that was suitable for comprehensive pteridine analysis in urine. The method was applied to a comparative study of commonly used oxidative pretreatments for pteridine analysis, revealing that oxidative mechanisms were inefficient, complex, and concentration dependent. These quantitative findings compellingly demonstrate that oxidative pretreatments are problematic for pterinomics approaches. In addition, 50 clinical urine specimens were examined with the new technique wherein 10 pteridine derivatives were quantified and population ranges have been given. The urinary levels reported in this study were generally consistent with previous work and indicated the suitability of the new technique for urinary pteridine analysis. Finally, this technique can be used to examine pteridine molecular epidemiology and biochemistry to support related research applications, and may further be readily extended to additional pteridine derivatives and biological matrices for specific applications. 


\section{Acknowledgements}

Special thanks are given to Dr. Nathan Leigh of Missouri University of Science and

Technology for his valuable assistance in the interpretation of unknown mass spectral features,

and to V. Roger Holden, M.D. and Pearlena Hamlet, RN of Mercy Breast Center - Springfield

for their generous and enthusiastic support for this study. C. Burton received financial support

through a National Science Foundation Graduate Research Fellowship (\#DGE-1011744). The

project was financially supported by Department of Chemistry and Center for Single Cell, Single

Nanoparticle, and Single Molecule Monitoring, Missouri University of Science and Technology. 


\section{References}

[1] F. Hopkins, Note on a yellow pigment in butterflies, Nature, 40 (1889) 335.

[2] R. Purrmann, Über die Flügelpigmente der Schmetterlinge. VII. Synthese des Leukopterins und Natur des Guanopterins, Justus Liebigs Annalen der Chemie, 544 (1940) 182-190.

[3] R. Purrmann, Die Synthese des Xanthopterins. Über die Flügelpigmente der Schmetterlinge. X3, Justus Liebigs Annalen der Chemie, 546 (1941) 98-102.

[4] R. Purrmann, Konstitution und Synthese des sogenannten Anhydroleukopterins. Über die Flügelpigmente der Schmetterlinge XII, Justus Liebigs Annalen der Chemie, 548 (1941) 284-292.

[5] P. Kośliński, R. Bujak, E. Daghir, M.J. Markuszewski, Metabolic profiling of pteridines for determination of potential biomarkers in cancer diseases, Electrophoresis, 32 (2011) 2044-2054.

[6] N. Makoto, M. Wakako, T. Tsutomu, O. Miyuki, P. Kasan, Inhibition of tryptophan hydroxylase by dopamine and the precursor amino acids, Biochemical pharmacology, 48 (1994) 207-210.

[7] L. Wang, H. Erlandsen, J. Haavik, P.M. Knappskog, R.C. Stevens, Three-dimensional structure of human tryptophan hydroxylase and its implications for the biosynthesis of the neurotransmitters serotonin and melatonin, Biochemistry, 41 (2002) 12569-12574.

[8] B. Thony, G. Auerbach, N. Blau, Tetrahydrobiopterin biosynthesis, regeneration and functions, Biochem. J, 347 (2000) 1-16.

[9] S.S. Gross, R. Levi, Tetrahydrobiopterin synthesis. An absolute requirement for cytokine-induced nitric oxide generation by vascular smooth muscle, Journal of Biological Chemistry, 267 (1992) 25722-25729.

[10] C. Huber, D. Fuchs, A. Hausen, R. Margreiter, G. Reibnegger, M. Spielberger, H. Wachter, Pteridines as a new marker to detect human $\mathrm{T}$ cells activated by allogeneic or modified self major histocompatibility complex (MHC) determinants, The Journal of Immunology, 130 (1983) 1047-1050.

[11] G. Reibnegger, H. Hetzel, D. Fuchs, L.C. Fuith, A. Hausen, E.R. Werner, H. Wachter, Clinical significance of neopterin for prognosis and follow-up in ovarian cancer, Cancer research, 47 (1987) 4977-4981.

[12] T. Fukushima, T. Shiota, Biosynthesis of biopterin by Chinese hamster ovary (CHO K1) cell culture, Journal of biological chemistry, 249 (1974) 4445-4451.

[13] Y. Ma, C. Burton, Pteridine detection in urine: the future of cancer diagnostics?, Biomarkers in Medicine, 7 (2013) 679-681.

[14] C. Lorente, G. Petroselli, M.L. Dántola, E. Oliveros, A.H. Thomas, Electron transfer initiated reactions photoinduced by pterins, Pteridines, 22 (2011) 111-119.

[15] A.H. Thomas, C. Lorente, A.L. Capparelli, C.G. Martínez, A.M. Braun, E. Oliveros, Singlet oxygen (1 $\Delta \mathrm{g})$ production by pterin derivatives in aqueous solutions, Photochemical \& Photobiological Sciences, 2 (2003) 245-250.

[16] F.M. Cabrerizo, A.H. Thomas, C. Lorente, M.L. Dántola, G. Petroselli, R. Erra-Balsells, A.L. Capparelli, Generation of Reactive Oxygen Species during the Photolysis of 

349-365.

[17] G. Petroselli, J.M. Bartsch, A.H. Thomas, Photoinduced Generation of $\mathrm{H} 2 \mathrm{O} 2$ and O2•-by 6-formylpterin in Aqueous Solutions, Pteridines, 17 (2006) 82-89.

[18] M.P. Denofrio, S. Hatz, C. Lorente, F.M. Cabrerizo, P.R. Ogilby, A.H. Thomas, The photosensitizing activity of lumazine using 2'-deoxyguanosine 5'-monophosphate and HeLa cells as targets, Photochemical \& Photobiological Sciences, 8 (2009) 1539-1549.

[19] M.P. Serrano, C. Lorente, C.D. Borsarelli, A.H. Thomas, Unraveling the Degradation Mechanism of Purine Nucleotides Photosensitized by Pterins: The Role of Charge-Transfer Steps, ChemPhysChem, (2015).

[20] M.P. Serrano, C. Lorente, F.E.M. Vieyra, C.D. Borsarelli, A.H. Thomas, Photosensitizing properties of biopterin and its photoproducts using 2'-deoxyguanosine 5'-monophosphate as an oxidizable target, Physical Chemistry Chemical Physics, 14 (2012) 11657-11665.

[21] M.L. Dántola, M.P. Denofrio, B. Zurbano, C.S. Gimenez, P.R. Ogilby, C. Lorente, A.H. Thomas, Mechanism of photooxidation of folic acid sensitized by unconjugated pterins, Photochemical \& Photobiological Sciences, 9 (2010) 1604-1612.

[22] A.H. Thomas, M.P. Serrano, V. Rahal, P. Vicendo, C. Claparols, E. Oliveros, C. Lorente, Tryptophan oxidation photosensitized by pterin, Free Radical Biology and Medicine, 63 (2013) 467-475.

[23] J.F. Ross, P.K. Chaudhuri, M. Ratnam, Differential regulation of folate receptor isoforms in normal and malignant tissues in vivo and in established cell lines. Physiologic and clinical implications, Cancer, 73 (1994) 2432-2443.

[24] S.D. Weitman, R.H. Lark, L.R. Coney, D.W. Fort, V. Frasca, V.R. Zurawski, B.A. Kamen, Distribution of the folate receptor GP38 in normal and malignant cell lines and tissues, Cancer research, 52 (1992) 3396-3401.

[25] M. Wu, W. Gunning, M. Ratnam, Expression of folate receptor type $\alpha$ in relation to cell type, malignancy, and differentiation in ovary, uterus, and cervix, Cancer epidemiology biomarkers \& prevention, 8 (1999) 775-782.

[26] S. Gamagedara, S. Gibbons, Y. Ma, Investigation of urinary pteridine levels as potential biomarkers for noninvasive diagnosis of cancer, Clinica Chimica Acta, 412 (2011) 120-128.

[27] F. Han, B.H. Huynh, H. Shi, B. Lin, Y. Ma, Pteridine analysis in urine by capillary electrophoresis using laser-induced fluorescence detection, Analytical chemistry, 71 (1999) 1265-1269.

[28] P. Kośliński, P. Jarzemski, M.J. Markuszewski, R. Kaliszan, Determination of pterins in urine by HPLC with UV and fluorescent detection using different types of chromatographic stationary phases (HILIC, RP C 8, RP C 18), Journal of pharmaceutical and biomedical analysis, 91 (2014) 37-45.

[29] C. Burton, H. Shi, Y. Ma, Simultaneous Detection of Six Urinary Pteridines and Creatinine by High-Performance Liquid Chromatography-Tandem Mass Spectrometry for Clinical Breast Cancer Detection, Analytical chemistry, 85 (2013) 11137-11145.

[30] C. Burton, H. Shi, Y. Ma, Normalization of urinary pteridines by urine specific gravity for 
[31] M. Konishi, K. Shibasaki, K. Hiroyasu, S. Toya, T. Kuwahara, A. Yamaguchi, K. Tsuchikawa, I. Mataga, N. Yohkoh, Y. Adachi, Clinical evaluation of urinary 6-hydroxymethylpterin (6-HMP) in patients with cancer of the digestive organs, Shigaku= Odontology, 86 (1999) 849-853.

[32] S. Manjula, A.R. Aroor, A. Raja, S. Rao, A. Rao, Urinary excretion of 6-hydroxymethylpterin in brain tumours, Acta Oncologica, 32 (1993) 29-31.

[33] C. Burton, Y. Dan, A. Donovan, K. Liu, H. Shi, Y. Ma, C.P. Bosnak, Urinary metallomics as a novel biomarker discovery platform: Breast cancer as a case study, Clinica Chimica Acta, 452 (2016) 142-148.

[34] H. Rembold, W.L. Gyure, Biochemistry of the pteridines, Angewandte Chemie International Edition in English, 11 (1972) 1061-1072.

[35] S.E. Gibbons, I. Stayton, Y. Ma, Optimization of urinary pteridine analysis conditions by CE-LIF for clinical use in early cancer detection, Electrophoresis, 30 (2009) 3591-3597.

[36] H. Tomšíková, P. Solich, L. Nováková, Sample preparation and UHPLC-FD analysis of pteridines in human urine, Journal of pharmaceutical and biomedical analysis, 95 (2014) 265-272.

[37] E.M. Tornero, I.D. Merás, A. Espinosa-Mansilla, HPLC determination of serum pteridine pattern as biomarkers, Talanta, 128 (2014) 319-326.

[38] P. Guibal, N. Lévêque, D. Doummar, N. Giraud, E. Roze, D. Rodriguez, R. Couderc, T. Billette De Villemeur, F. Moussa, Simultaneous determination of all forms of biopterin and neopterin in cerebrospinal fluid, ACS chemical neuroscience, 5 (2014) 533-541.

[39] A.M. de Llanos, A. Espinosa-Mansilla, F. Cañada-Cañada, A.M. de la Peña, Separation and determination of 11 marker pteridines in human urine by liquid chromatography and fluorimetric detection, Journal of separation science, 34 (2011) 1283-1292.

[40] M. Culzoni, A.M. de Llanos, M. De Zan, A. Espinosa-Mansilla, F. Cañada-Cañada, A.M. de la Peña, H. Goicoechea, Enhanced MCR-ALS modeling of HPLC with fast scan fluorimetric detection second-order data for quantitation of metabolic disorder marker pteridines in urine, Talanta, 85 (2011) 2368-2374.

[41] A.J. Girón, E. Martín-Tornero, M.H. Sánchez, I.D. Merás, A.E. Mansilla, A simple HPLC-ESI-MS method for the direct determination of ten pteridinic biomarkers in human urine, Talanta, 101 (2012) 465-472.

[42] C. Burton, R. Weng, L. Yang, Y. Bai, H. Liu, Y. Ma, High-throughput intracellular pteridinic profiling by liquid chromatography-quadrupole time-of-flight mass spectrometry, Analytica chimica acta, 853 (2015) 442-450.

[43] J. Van Daele, D. Blancquaert, F. Kiekens, D. Van Der Straeten, W.E. Lambert, C.P. Stove, Degradation and interconversion of plant pteridines during sample preparation and ultra-high performance liquid chromatography-tandem mass spectrometry, Food chemistry, 194 (2016) 1189-1198.

[44] G. Allegri, H.J.B. Costa Netto, L.N.L. Ferreira Gomes, M.L. Costa de Oliveira, F.B. Scalco, F.R. de Aquino Neto, Determination of six pterins in urine by LC-MS/MS, Bioanalysis, 4 (2012) 
[45] X. Xiong, Y. Liu, Chromatographic behavior of 12 polar pteridines in hydrophilic interaction chromatography using five different HILIC columns coupled with tandem mass spectrometry, Talanta, 150 (2016) 493-502.

[46] L. Huang, L. Guo, Y. Wan, P. Pan, L. Feng, Simultaneous determination of three potential cancer biomarkers in rat urine by synchronous fluorescence spectroscopy, Spectrochimica Acta Part A: Molecular and Biomolecular Spectroscopy, 120 (2014) 595-601.

[47] Y.-Q. Wan, L.-J. Tang, T. Tan, Simultaneous determination of xanthopterin and isoxanthopterin in human urine by synchronous fluorescence spectroscopy, Journal of fluorescence, 20 (2010) 1191-1198.

[48] M.D. Davis, S. Kaufman, S. Milstien, Conversion of 6-substituted tetrahydropterins to 7 -isomers via phenylalanine hydroxylase-generated intermediates, Proceedings of the National Academy of Sciences, 88 (1991) 385-389.

[49] H.-C. Curtius, A. Matasovic, G. Schoedon, T. Kuster, P. Guibaud, T. Giudici, N. Blau, 7-Substituted pterins. A new class of mammalian pteridines, Journal of Biological Chemistry, 265 (1990) 3923-3930.

[50] Tomšíková H, Tomšík P, Solich P, N. L, Determination of pteridines in biological samples with an emphasis on their stability, Bioanalysis, 5 (2013) 2307-2326.

[51] P. Guibal, N. Lévêque, D. Doummar, N. Giraud, E. Roze, D. Rodriguez, R. Couderc, T. Billette De Villemeur, F. Moussa, Simultaneous determination of all forms of biopterin and neopterin in cerebrospinal fluid, ACS chemical neuroscience, (2014).

[52] L. Fismen, T. Eide, R. Djurhuus, A.M. Svardal, Simultaneous quantification of tetrahydrobiopterin, dihydrobiopterin, and biopterin by liquid chromatography coupled electrospray tandem mass spectrometry, Analytical biochemistry, 430 (2012) 163-170.

[53] G. Reibnegger, D. Fuchs, A comment to "Normalization of urinary pteridines by urine specific gravity for early cancer detection"'[Clin. Chim. Acta 435 (2014) 42-47], Clinica Chimica Acta, (2015) 418-419.

[54] Y. Ma, C. Burton, H. Shi, A rebuttal to "A comment to "Normalization of urinary pteridines by urine specific gravity for early cancer detection'[Clin. Chim. Acta 435 (2014) 42-47]", Clinica Chimica Acta, 438 (2015) 415-417.

[55] C. Burton, H. Shi, Y. Ma, Daily variation and effect of dietary folate on urinary pteridines, Metabolomics, 12 (2016) 1-10.

[56] L. Wang, Y. Chai, P. Tu, C. Sun, Y. Pan, Formation of $[\mathrm{M}+15]+$ ions from aromatic aldehydes by use of methanol: in-source aldolization reaction in electrospray ionization mass spectrometry, Journal of Mass Spectrometry, 46 (2011) 1203-1210.

[57] M. Johansson, J. Jastrebova, A. Grahn, M. Jägerstad, Separation of dietary folates by gradient reversed-phase HPLC: comparison of alternative and conventional silica-based stationary phases, Chromatographia, 62 (2005) 33-40.

[58] M. Niesser, H. Demmelmair, T. Weith, D. Moretti, A. Rauh-Pfeiffer, M. van Lipzig, W. Vaes, B. Koletzko, W. Peissner, Folate catabolites in spot urine as non-invasive biomarkers of folate status during habitual intake and folic acid supplementation, PloS one, 8 (2013) e56194. 
[59] M.L. Dántola, M. Vignoni, C. González, C. Lorente, P. Vicendo, E. Oliveros, A.H. Thomas, Electron-transfer processes induced by the triplet state of pterins in aqueous solutions, Free Radical Biology and Medicine, 49 (2010) 1014-1022. 
Table 1. A summary of recently developed quantitative analytical methodologies for biogenic pteridines.

\begin{tabular}{|c|c|c|c|c|}
\hline Technique & Pteridines $^{1}$ & $\begin{array}{c}\text { Oxidative } \\
\text { Pretreatment }\end{array}$ & Run Time (min) ${ }^{2}$ & Reference \\
\hline CE-LIF & $\begin{array}{l}\text { PTE, XAN, ISO, NEO, 6-BIO, 6-CAP, } \\
\text { 6,7-DMP, 6-HMP }\end{array}$ & Alkaline $\mathrm{I}_{3}^{-}$ & 20 & $\begin{array}{c}\text { Gibbons et al } \\
\text { (2009)[35] }\end{array}$ \\
\hline HPLC-FD & PTE, NEO, 6-BIO, XAN, ISO & None & 16 & $\begin{array}{l}\text { De Llanos et al } \\
\text { (2011)[39] }\end{array}$ \\
\hline HPLC-FD & $\begin{array}{l}\text { PTE, XAN, ISO, NEO, 6-BIO, 7-BIO, } \\
\text { MNP, 6-CAP, 6-HMP, LUM, } \\
\text { 6-HLUM, 7-HLUM, BLUM }\end{array}$ & $\begin{array}{l}\text { Alkaline } \mathrm{I}_{3}^{-} \\
\text {and } \mathrm{KMnO}_{4}\end{array}$ & 39 & $\begin{array}{l}\text { De Llanos et al } \\
\text { (2011)[39] }\end{array}$ \\
\hline HPLC-FD & PTE, NEO, 6-BIO; XAN, ISO & None & 16 & $\begin{array}{l}\text { Culzoni et al } \\
(2011)[40]\end{array}$ \\
\hline HPLC-MS/MS & PTE, ISO, 6-BIO, 7-BIO, NEO, MNP & Acidic $\mathrm{MnO}_{2}$ & 19 & $\begin{array}{l}\text { Allegri et al } \\
(2012)[44]\end{array}$ \\
\hline HPLC-MS & $\begin{array}{l}\text { PTE, XAN, ISO, NEO, MNP, NH2, } \\
\text { 6-BIO, BH2, 6-HMP, 6-MP, 6-CAP }\end{array}$ & None & 30 & $\begin{array}{l}\text { Girón et al } \\
(2012)[41]\end{array}$ \\
\hline HPLC-MS/MS & $\begin{array}{l}\text { PTE, XAN, ISO, NEO, 6-BIO, 6-CAP, } \\
\text { 6,7-DMP, 6-HMP }\end{array}$ & Alkaline $I_{3}^{-}$ & 7.5 & $\begin{array}{c}\text { Burton et al } \\
(2013)[29]\end{array}$ \\
\hline HPLC-FD & 6-BIO, BH2, BH4, NEO, NH2 & None & 16 & $\begin{array}{l}\text { Guibal et al } \\
(2014)[38]\end{array}$ \\
\hline HPLC-FD & $\begin{array}{l}\text { PTE, XAN, ISO, NEO, 6-BIO, 6-CAP, } \\
\text { 6,7-DMP, 6-HMP }\end{array}$ & $\begin{array}{l}\text { Alkaline } \mathrm{I}_{3}^{-} \\
\text {and } \mathrm{KMnO}_{4}\end{array}$ & 25 & $\begin{array}{l}\text { Kośliński et al } \\
\text { (2014)[28] }\end{array}$ \\
\hline HPLC-FD & $\begin{array}{l}\text { PTE, XAN, ISO, NEO, MNP, 6-BIO, } \\
\text { 7-BIO, 6-CAP, 6-HMP }\end{array}$ & 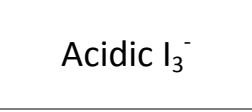 & 29 & $\begin{array}{l}\text { Tornero et al } \\
(2014)[37]\end{array}$ \\
\hline HPLC-MS/MS & $\begin{array}{l}\text { Quantitative: PTE, XAN, ISO, NEO, } \\
\text { 6-BIO, 6-CAP, 6,7-DMP, 6-HMP } \\
\text { Semi-quantitative: LUM, PH2, PH4, } \\
\text { 6-MP, 6-HLUM, 7-HLUM, XH2, } \\
\text { 6-FOP, 6,7-DMH4P; BH2, BLUM, } \\
\text { BH2, BH4, MNP, NH2, NH4 }\end{array}$ & None & 25 & $\begin{array}{l}\text { Burton et al } \\
(2015)[42]\end{array}$ \\
\hline UHPLC-MS/MS & $\begin{array}{l}\text { PTE, XAN, XH2, NEO, NH2, 6-HMP, } \\
\text { 6-HMDP, 6-FOP, 6-CAP }\end{array}$ & $\mathrm{Mn}_{2} \mathrm{O}_{5}$ & 8 & $\begin{array}{c}\text { Van Daele et al } \\
\text { (2016)[43] }\end{array}$ \\
\hline $\begin{array}{c}\text { Proposed } \\
\text { HPLC-MS/MS }\end{array}$ & $\begin{array}{l}\text { PTE, XAN, XH2, ISO, NEO, MNP, } \\
\text { 6-BIO, SEP, 6-CAP, 6,7-DMP, 6-MP, } \\
\text { 6-HMP, LUM, 6-HLUM, 7-HLUM }\end{array}$ & None & 7 & -- \\
\hline $\begin{array}{l}{ }^{1} \text { PTE: Pterin; } \\
\text { 6-Carboxypterin; } \\
\text { Monapterin; LUM }\end{array}$ & $\begin{array}{l}\text { KAN: Xanthopterin; ISO: Isoxanthopte } \\
\text { 6,7-DMP: 6,7-Dimethylpterin; 6-HMP } \\
\text { : Lumazine; 6-HLUM: 6-Hydroxylumazir }\end{array}$ & $\begin{array}{l}\text { :rin; NEO: Neop } \\
\text { 6-Hydroxmethy } \\
\text { e; 7-HLUM: 7-Hy }\end{array}$ & $\begin{array}{l}\text { terin; 6-BIO: 6-Bi } \\
\text { lpterin; 7-BIO: } 7-\mathrm{E} \\
\text { droxylumazine; BLL }\end{array}$ & $\begin{array}{l}\text { pterin; 6-CAP: } \\
\text { iopterin; MNP: } \\
\text { M: Biolumazine; }\end{array}$ \\
\hline
\end{tabular}


7,8-Dihydroxanthopterin; PH2: Dihydropterin; PH4: Tetrahydropterin; 6,7-Dimethyltetrahydrobiopterin; NH4: Tetrahydroneopterin; 6-HMDP: 6-Hydroxymethyldihydropterin; 6-FOP: 6-Formylpterin; SEP: Sepiapterin;

\footnotetext{
${ }^{2}$ Run time includes pre- and post-equilibration and cleaning procedures.
} 
Table 2. Optimized ion pairs for MRM detection. Unlabeled ion pairs located directly below a labeled compound represent confirmation ion pairs.

\begin{tabular}{|c|c|c|c|c|}
\hline Compound & $\begin{array}{l}\text { Ion Pairs } \\
(\mathrm{m} / \mathrm{z})\end{array}$ & $\begin{array}{l}\text { Declustering Potential } \\
\qquad(D P, V)\end{array}$ & $\begin{array}{l}\text { Collision Energy } \\
\text { (CE, V) }\end{array}$ & $\begin{array}{l}\text { Collision Cell Potential } \\
\text { (CXP, V) }\end{array}$ \\
\hline \multirow[t]{2}{*}{ 6-Carboxypterin } & 208.1/164.3 & 46 & 23 & 10 \\
\hline & 208.1/190.1 & 46 & 21 & 12 \\
\hline \multirow[t]{2}{*}{ 6,7-Dimethylpterin } & $192.2 / 165.2$ & 11 & 31 & 10 \\
\hline & 192.2/106.2 & 11 & 39 & 6 \\
\hline \multirow[t]{2}{*}{ 6-Formylpterin } & 192.1/147.2 & 76 & 31 & 8 \\
\hline & 192.1/149.2 & 76 & 29 & 8 \\
\hline \multirow[t]{2}{*}{ 6-Hydroxylumazine } & 181.1/164.2 & 76 & 23 & 10 \\
\hline & 181.1/108.1 & 76 & 35 & 6 \\
\hline \multirow[t]{2}{*}{ 6-Hydroxymethylpterin } & 194.1/106.1 & 61 & 37 & 18 \\
\hline & 194.1/176.2 & 61 & 23 & 12 \\
\hline \multirow[t]{2}{*}{ 6-Methylpterin } & 178.2/106.1 & 1 & 41 & 6 \\
\hline & $178.2 / 133.2$ & 1 & 31 & 8 \\
\hline \multirow[t]{2}{*}{ 7,8-Dihydroxanthopterin } & $182.1 / 126.2$ & 71 & 29 & 22 \\
\hline & $182.1 / 154.2$ & 71 & 25 & 10 \\
\hline \multirow[t]{2}{*}{ 7-Hydroxylumazine } & 181.1/110.1 & 76 & 31 & 6 \\
\hline & $181.1 / 55.2$ & 76 & 49 & 8 \\
\hline \multirow[t]{2}{*}{ Biopterin } & $238.1 / 220.2$ & 66 & 23 & 14 \\
\hline & 238.1/178.3 & 66 & 29 & 12 \\
\hline \multirow[t]{2}{*}{ Folic Acid } & $442.2 / 176.3$ & 56 & 55 & 10 \\
\hline & $442.2 / 295.4$ & 56 & 21 & 8 \\
\hline \multirow[t]{2}{*}{ Isoxanthopterin } & 180.1/135.1 & 71 & 33 & 8 \\
\hline & 180.1/163.2 & 71 & 27 & 10 \\
\hline \multirow[t]{2}{*}{ Lumazine } & 165.1/69.1 & 71 & 55 & 12 \\
\hline & $165.1 / 93.1$ & 71 & 41 & 4 \\
\hline \multirow[t]{2}{*}{ Monapterin } & 254.1/206.1 & 71 & 27 & 14 \\
\hline & $254.1 / 236.3$ & 71 & 21 & 16 \\
\hline \multirow[t]{2}{*}{ Neopterin } & $254.0 / 206.2$ & 76 & 27 & 12 \\
\hline & $254.0 / 236.3$ & 76 & 23 & 16 \\
\hline \multirow[t]{2}{*}{ Pterin } & 164.1/92.1 & 71 & 43 & 4 \\
\hline & 164.1/119.1 & 71 & 33 & 6 \\
\hline \multirow[t]{2}{*}{ Sepiapterin } & 238.1/192.3 & 61 & 23 & 12 \\
\hline & 238.1/165.3 & 61 & 33 & 10 \\
\hline \multirow[t]{2}{*}{ Xantopterin } & $180.1 / 135.2$ & 76 & 31 & 24 \\
\hline & $180.1 / 163.1$ & 76 & 25 & 10 \\
\hline
\end{tabular}


Table 3. Effect of oxidative pretreatment on pteridines in synthetic urine.

\begin{tabular}{|c|c|c|c|c|c|c|}
\hline Compound & $\begin{array}{c}15 \mu \mathrm{M} \\
\text { alkaline } \mathrm{I}_{3}^{-}\end{array}$ & $\begin{array}{c}15 \mu \mathrm{M} \\
\text { acidic } \mathrm{I}_{3}^{-}\end{array}$ & $\begin{array}{c}150 \mu \mathrm{M} \\
\text { alkaline } \mathrm{I}_{3}^{-}\end{array}$ & $\begin{array}{c}150 \mu \mathrm{M} \\
\text { acidic } \mathrm{I}_{3}^{-}\end{array}$ & $\mathrm{KMnO}_{4}$ & $\begin{array}{l}\text { Acidic } \\
\mathrm{MnO}_{2}\end{array}$ \\
\hline Isoxanthopterin & $102 \%$ & $104 \%$ & $100 \%$ & $100 \%$ & $73 \%$ & $83 \%$ \\
\hline 6,7-Dimethylpterin & $102 \%$ & $114 \%$ & $106 \%$ & $99 \%$ & $88 \%$ & $103 \%$ \\
\hline Pterin & $99 \%$ & $106 \%$ & $51 \%$ & $103 \%$ & $31 \%$ & $95 \%$ \\
\hline 6-Hydroxymethylpterin & $97 \%$ & $110 \%$ & $107 \%$ & $114 \%$ & $40 \%$ & $83 \%$ \\
\hline 6-Biopterin & $96 \%$ & $96 \%$ & $86 \%$ & $92 \%$ & $91 \%$ & $93 \%$ \\
\hline 6-Methylpterin & $94 \%$ & $79 \%$ & $78 \%$ & $48 \%$ & $93 \%$ & $88 \%$ \\
\hline Neopterin & $93 \%$ & $81 \%$ & $87 \%$ & $80 \%$ & $45 \%$ & $81 \%$ \\
\hline 7-Hydroxylumazine & $91 \%$ & $95 \%$ & $79 \%$ & $73 \%$ & $37 \%$ & $67 \%$ \\
\hline Lumazine & $91 \%$ & $108 \%$ & $79 \%$ & $85 \%$ & $35 \%$ & $98 \%$ \\
\hline Monapterin & $85 \%$ & $102 \%$ & $72 \%$ & $74 \%$ & $41 \%$ & $89 \%$ \\
\hline Xanthopterin & $80 \%$ & $0 \%$ & $63 \%$ & $0 \%$ & $0 \%$ & $67 \%$ \\
\hline 6-Carboxypterin & $68 \%$ & $72 \%$ & $76 \%$ & $52 \%$ & $49 \%$ & $74 \%$ \\
\hline 6-Hydroxylumazine & $62 \%$ & $0 \%$ & $63 \%$ & $0 \%$ & $26 \%$ & $47 \%$ \\
\hline Sepiapterin & $0 \%$ & $0 \%$ & $0 \%$ & $0 \%$ & $0 \%$ & $0 \%$ \\
\hline 7,8-Dihydroxanthopterin & $0 \%$ & $0 \%$ & $0 \%$ & $0 \%$ & $0 \%$ & $0 \%$ \\
\hline
\end{tabular}

${ }^{\dagger}$ All values are expressed as a percentage of the untreated control group.

${ }^{\star}$ Samples were run in triplicate at a concentration of $5 \mu \mathrm{g} / \mathrm{L}$. 
Table 4. Performance characteristics of the pterinomics workflow.

Compound

\begin{tabular}{cc} 
Retention & Linear Range \\
Time $(\min )$ & $\left(\mu g \mathbf{L}^{-1}\right)$ \\
\hline
\end{tabular}

11 Neopterin

2.2

$0.1-500$

$\mathbf{R}^{2}$

MDLs

LLOQs Rec

12Monapterin

13

14Xantopterin

2.3

0.9997
$\left.(\mu \mathrm{g} \mathrm{L})^{-1}\right)$

$\left(\mu \mathrm{g} \mathrm{L}^{-1}\right)$

Recovery \%

Recovery \%

Recovery \% Urinary

15 ,8-Dihydroxanthopterin

$0.1-500$

0.9982

0.05

0.1

$0.3-500$

0.9995

0.05

0.1

2.75

$0.5-1000$

0.9825

0.2

0.3

$0.1-500$

0.9997

0.3

0.5

2.9

$0.05-500$

0.05

0.1

$0.9983 \quad 0.025$

0.05

$0.3-500$

0.9992

0.2

0.3

3.1

$0.1-500$

0.9992

0.05

0.1

$1-500$

0.9955

0.5

$0.5-500$

0.9981

0.3

1

0.5

3.8

$0.2-500$

0.9982

0.1

0.2

$0.5-500$

0.9993

0.3

0.5

4.1

$0.05-500$

0.9992

0.05

0.1

$0.1-500 \quad 0.9995$

0.05

0.1

$0.1-500$

0.9995

0.05

0.1

96

105

94

91

97

101

96

97

87

94

94
94

$(10 \mu \mathrm{g}$
97

\begin{tabular}{ccc}
$\left.\boldsymbol{\mu} \mathbf{g ~ L}^{-1}\right)^{1}$ & $\left(\mathbf{1 0 0} \boldsymbol{\mu} \mathbf{g ~ L}^{-1}\right)^{1}$ & Range $(\mathbf{n M})$ \\
\hline 97 & 102 & $180-26,300$ \\
100 & 97 & $50-2400$ \\
100 & 97 & $320-6000$ \\
94 & 112 & $5000-112,000$ \\
98 & 97 & $110-9700$ \\
95 & 94 & N.D.
\end{tabular}

88

96

92

103

105

250-2010

5.2

${ }^{1}$ Recovery of pteridine standards spiked into a urine sample at the designated concentrations $(n=5)$. No oxidative pretreatment was used. 


\section{Figure Captions}

Figure 1. Chemical structures of the 15 pteridine derivatives: (1) pterin, (2) xanthopterin, (3) isoxanthopterin, (4) 7,8-dihydroxanthopterin, (5) 6-carboxypterin, (6) 6-hydroxymethylpterin, (7) 6,7-dimethylpterin, (8) 6-methylpterin, (9) neopterin, (10) L-monapterin, (11) 6-biopterin, (12) sepiapterin, (13) lumazine, (14) 6-hydroxylumazine, and (15) 7-hydroxylumazine.

Figure 2. Overlaid extracted ion chromatograms (XIC) of the quantitative ion pairs of fifteen pteridine derivatives prepared at $10 \mu \mathrm{g} / \mathrm{L}$ in synthetic urine. Separation parameters: Column, Luna phenyl-hexyl $(3.0 \mu \mathrm{m}, 3.0 \times 150 \mathrm{~mm})$; Flow rate, $0.45 \mathrm{~mL} / \mathrm{min}$; Injection volume, $50 \mu \mathrm{L}$; Mobile phase: A: $0.025 \%$ formic acid in $99 \%$ ultra-pure water / $1 \%$ acetonitrile; B: methanol; Gradient flow: Linear increase from $7 \%$ B to $20 \%$ for two minutes, $20 \%$ B for two minutes, rapid decrease to $7 \% \mathrm{~B}$ for two minutes.

Figure 3. Overlaid extracted ion chromatograms (XIC) of the quantitative and confirmation ion pairs of native pteridine derivatives in 100-fold diluted urine with a typical USG of 1.014. Only detectable transitions (signal-to-noise ratio > 3) are shown. 


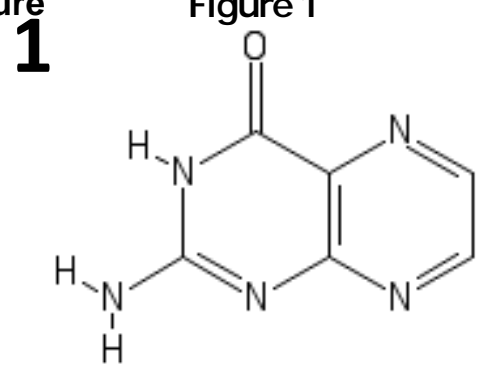

5

9

11

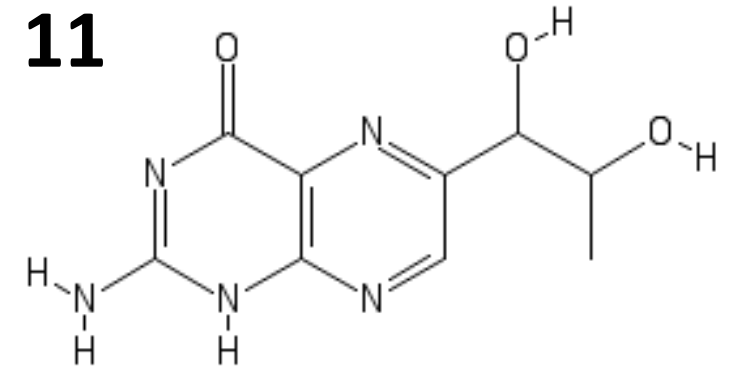<smiles>NNc1nc(=O)c2[nH]c(=O)cnc2[nH]1</smiles><smiles>Nc1nc2[nH]c(=O)cnc2c(=O)[nH]1</smiles><smiles>O=c1nc(N[O-])[nH]c2ncc(CO)nc12</smiles><smiles>Cc1nc2[nH]c(N)nc(=O)c2nc1C</smiles><smiles></smiles>

12<smiles>CC1=NC(NN)=NC2=C(NCN2)N1</smiles>

4<smiles>NNc1nc(=O)c2c([nH]1)NCC(=O)N2</smiles>

8<smiles>[H][Y]Nc1nc(=O)c2nc(C)cnc2[nH]1</smiles>

14

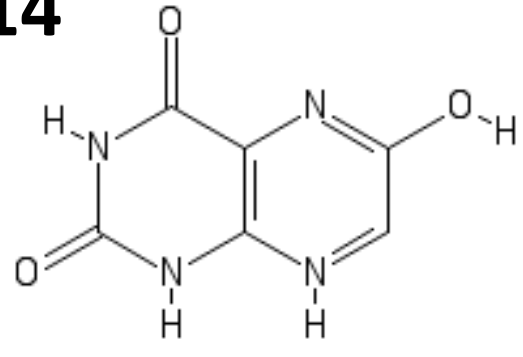

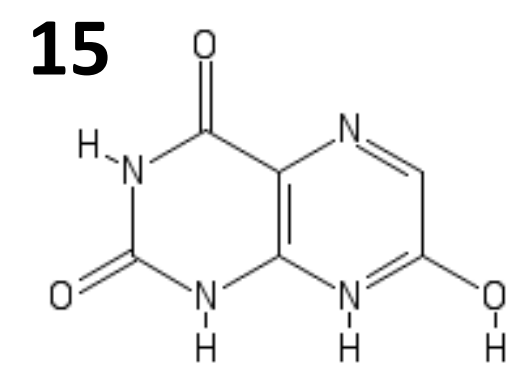




\section{Pteridines:}

1: Neopterin

2: Monapterin

3: Xanthopterin

4: Dihydroxanthopterin

5: 6-Biopterin

6: 6-Hydroxymethylpterin

7: Isoxanthopterin

8: Pterin

9: 6-Hydroxylumazine

10: Lumazine

11: 7-Hydroxylumazine

12: 6-Carboxypterin

13: 6-Methylpterin

14: Sepiapterin

15: 6,7-Dimethylpterin

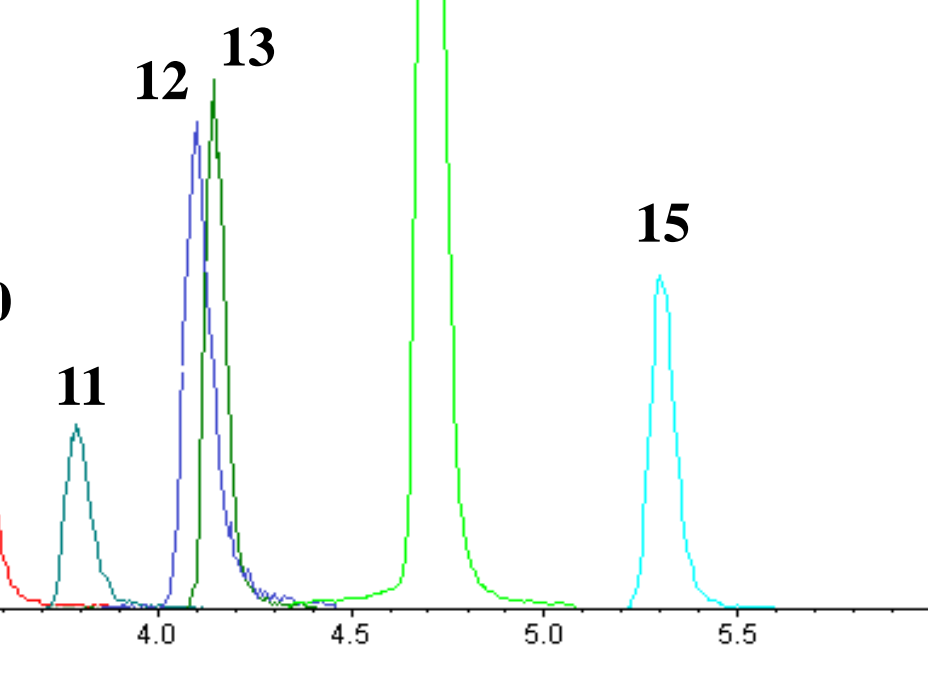


1: Neopterin

2: Monapterin

3: Xanthopterin

4: Dihydroxanthopterin

5: 6-Biopterin

2.2e4 6: Isoxanthopterin

2.0e4. 7: Pterin

8: Lumazine

\section{9: 7-Hydroxylumazine}

10: Sepiapterin 